Article

\title{
Experimental Investigation into the Effects of Thermal Recuperation on the Combustion Characteristics of a Non-Premixed Meso-Scale Vortex Combustor
}

\author{
Seyed Ehsan Hosseini ${ }^{1, *}$, Evan Owens ${ }^{1}$, John Krohn ${ }^{1}$ and James Leylek ${ }^{2}$ \\ 1 Combustion and Sustainable Energy Laboratory (ComSEL), Department of Mechanical Engineering, \\ Arkansas Tech University, 1811 N Boulder Ave, Russellville, AR 72801, USA; eowens@atu.edu (E.O.); \\ jkrohn@atu.edu (J.K.) \\ 2 Department of Mechanical Engineering, University of Arkansas at Fayetteville, College of Engineering, \\ 4183 Bell Engineering Center, Fayetteville, AR 72701, USA; jleylek@uark.edu \\ * Correspondence: shosseini@atu.edu or seyed.ehsan.hosseini@gmail.com; Tel.: +1-(479)-964-0877
}

Received: 4 November 2018; Accepted: 30 November 2018; Published: 4 December 2018

check for updates

\begin{abstract}
In small-scale combustors, the ratio of area to the combustor volume increases and hence heat loss from the combustor's wall is significantly enhanced and flame quenching occurs. To solve this problem, non-premixed vortex flow is employed to stabilize flames in a meso-scale combustion chamber to generate small-scale power or thrust for propulsion systems. In this experimental investigation, the effects of thermal recuperation on the characteristics of asymmetric non-premixed vortex combustion are studied. The exhaust gases temperature, emissions and the combustor wall temperature are measured to evaluate thermal and emitter efficiencies. The results illustrate that in both combustors (with/without thermal recuperator), by increasing the combustion air mass flowrate, the wall temperature increases while the wall temperature of combustor with thermal recuperator is higher. The emitter efficiency calculated based on the combustor wall temperature is significantly increased by using thermal recuperator. Thermal efficiency of the combustion system increases up to $10 \%$ when thermal recuperator is employed especially in moderate Reynolds numbers (combustion air flow rate is $120 \mathrm{mg} / \mathrm{s}$ ).
\end{abstract}

Keywords: meso-scale combustor; vortex; non-premixed; thermal efficiency; emitter efficiency

\section{Introduction}

Investigations about small-scale combustion systems have been developed in recent years due to the progress in the miniaturization of electric power generation for running low weight mechanical devices (micro-pumps/motors/airplanes/rovers). Considering efficient energy conversion of small-scale combustion systems, application of these devices instead of current traditional batteries would result in weight reduction and lifetime augmentation of the mechanical systems [1]. The functionality of portable micro-electro-mechanic-systems (MEMS) will be significantly improved by availability of high-performance small-scale power generators. Nevertheless, improvements in thermal and chemical management and proper diagnostic and control of the system would illustrate significant progress in the development of miniaturized combustion [2]. The increasing requests to reduce system weight, mitigate system cost and enhance unit operational lifetimes have encouraged MEMS investigators to study about various concepts behind of this new field [3]. One of the most important challenges in this new field is employing the high-specific energy of hydrocarbons in small-scale combustors to generate micro-power [4]. Since the transportation of liquid hydrocarbon fuels is easy and quite safe and they have 
significantly high-specific energy (averagely $45 \mathrm{MJ} / \mathrm{kg}$ ), they have been considered as the most important types of fuel for combustion-based micro-power generation [5].

In a meso-scale combustor, the time scale of heat transfer in the walls becomes comparable to the time scale of combustion due to the size reduction. Therefore, the temperature difference between the flame and structure decreases, leading to a condition that both normal flame and weak flame exist. By increasing the combustor's wall temperature, the ignition time becomes shorter, approaches the flow residence time and flame instability take places [6]. The variations in combustor's wall temperature has significant impacts on the meso-scale combustion when the Biot number (the ratio of diffusion time scale to the radiative and convective heat loss time scale) is not large. Moreover, the ratio of combustion time scale to the diffusion time scale in solid phase (Fourier number) plays an important role on the temperature distribution of wall temperature. In high Fourier numbers, the temperature distribution in the wall is considered quasi-steady-state. In miniaturized combustors, where the Knudsen number (the ratio of the molecular mean free path length to a representative physical length scale) is larger than 0.01 , the non-equilibrium transport influences on the ignition and extinction [7].

Since the ratio of area to volume increases in small-scale combustors, heat loss from the combustor's wall enhances drastically and flame quenching occurs because the combustor's wall acts like enthalpy sink and the heat of combustion cannot provide the heat loss to the surroundings through the wall [8]. Furthermore, inadequate residence time and stabilization of flame in small-scale combustor is another important issue in this field. Several solutions have been suggested to enhance flame stability and mitigate quenching limits as follow:

- Using inert porous media based on the concepts of heat transfer mechanisms and excess enthalpy where the solid porous medium is convectively heated by the flame and the heat is transferred upstream to preheat the inert mixture through radiation and conduction heat transfer [9].

- Catalytic combustion was proposed to enhance extinction limits, where the characteristic time scale of combustion is reduced in the presence of a catalytic surface [10].

- Vortex combustion was employed to stabilize flame in miniaturized combustor where a stable flame is achieved by a large, relatively quiescent, hot core flow which is formed by the recirculation of the flow along the chamber length [11].

- Recirculating heat to redistribute thermal energy within the chamber and minimize the heat loss to the surroundings [12].

The rate of heat release depends on both Reynolds number and equivalence ratio, as it has proportional relation by the mass of fuel consumed [13]. Increasing flammability in small-scale combustors has conducted the combustion researches to the heat recirculating systems. Investigations indicate the design of the small-scale combustor, as well as the walls of combustor have significant impacts on the flame dynamics, flame structure and its location [14]. To develop combustion-based micro-power generation devices, the Swiss-roll approach was developed to indirectly recirculate burned gas energy to the unburned fuel/air mixture in the combustor [15]. Kim et al. [12] pointed out when the heat loss in a miniature Swiss-roll combustor increases (due to different combustor materials), the flammability of the mixture becomes narrower. Chen and Buckmaster [16] stipulated when equivalence ratio or Reynolds number increases in a microscale Swiss-roll combustor, the reaction front is shifted from the center of the combustor towards the inlet due to the enhancement of reaction rate. Kim et al. [17] experimented a small-scale Swiss-Roll combustor using recirculation of heat from burned gases to the unburned air/fuel mixture to stabilize the flame and found the excess enthalpy of recirculated burned gases increases the flame peak temperature at the recirculation zone.

Although, applications of vortex combustion have been developed in meso-scale combustion [18], the effects of thermal recuperation have not been considered. Therefore, the goal of the present experimental investigation is to compare the performance of meso-scale vortex combustion with and without thermal recuperation. In this paper, vortex combustion is investigated to stabilize a non-premixed methane/air meso-scale combustion. Two miniaturized chambers as small as $5 \mathrm{~mm}$ with/without thermal 
recuperation were fabricated in Combustion and Sustainable Energy Laboratory (ComSEL) at Arkansas Tech University (ATU, Russellville, AR, USA) to investigate the effects of vortex combustion and thermal recuperation in meso-scale combustion simultaneously. The design of the system was done based on the concept of asymmetry swirl combustion proposed by Gabler et al. [19] which was proposed for macro-scale combustors. The impacts of heat loss on the propagation limit and flame quenching in meso-scale combustion is investigated considering flow velocity and equivalence ratio. Two meso-scale vortex combustion designs (with/without thermal recuperation) are experimentally investigated and compared in terms of flame stability, wall temperature, thermal efficiency and emissions. Tests are done at varying inlet air mass flow rates such as $40,80,120$ and $170 \mathrm{mg} / \mathrm{s}$, which correspond to Reynolds numbers of $1840,3681,5522$, and 7822, respectively.

\section{Experimental Setup}

Two non-premixed meso-scale vortex combustors have been fabricated in ComSEL at ATU, one with enhanced thermal recuperation and one without. The two combustors used in this study have combustion chambers with diameters $10 \mathrm{~mm}$ and fit within a $41 \mathrm{~cm}^{3}$ volume. Figure 1 shows the details of the small-scale combustors. Both designs are made from 1018 steel that was professionally machined and the dimensions are shown in Figure 2.

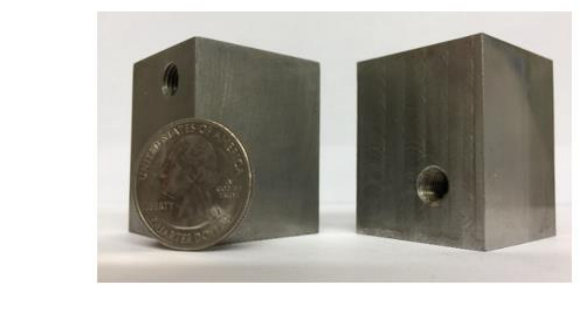

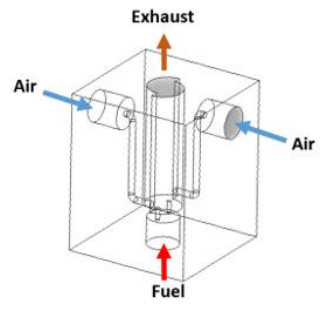

(a)

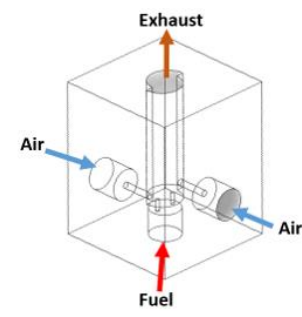

(b)

Figure 1. Schematic of meso-scale vortex combustor (a) with thermal recuperator (b) without thermal recuperator.

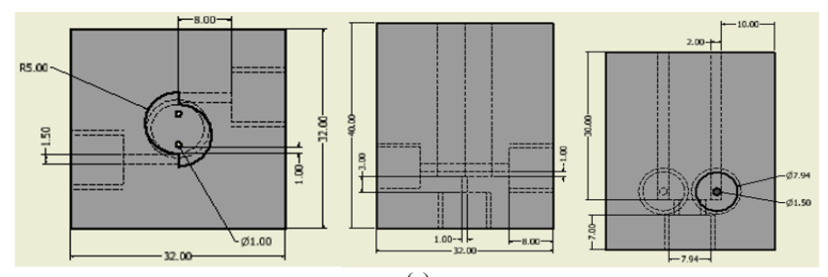

(a)

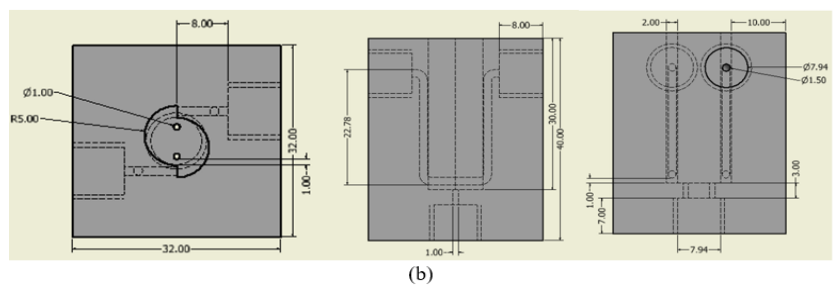

Figure 2. Details of meso-scale vortex combustor design (a) without thermal recuperator (b) with thermal recuperator (units in $\mathrm{mm}$ ). 
Air is provided by a large air compressor equipped with a pressure regulator and fuel is provided from a pressurized cylinder also equipped with a pressure regulator. A $99 \%$ pure methane is the fuel used during testing and different parameters are compared between the two different designs such as exhaust temperature, wall temperature, thermal efficiency, and emissions. Air and fuel flows are measured with digital flow meters that are calibrated and have a measuring range of 0.1 to $10 \mathrm{~L}$ per minute for air and 0.01 to $1 \mathrm{~L}$ per minute for fuel. Exhaust and wall temperatures are measured with K-type thermocouples with usb connection connected to a laptop computer (the uncertainty of $\pm 1.2^{\circ} \mathrm{C}$ ). The wall temperature is measured near the center of the side walls and the exhaust temperature is measured above the exhaust outlet, level with the surface of the combustor. The exhaust is analyzed using a combustion/emission analyzer (Ampro 2000, MRU) with uncertainty of $\pm 2{ }^{\circ} \mathrm{C}$ under $200{ }^{\circ} \mathrm{C}$ and an uncertainty of $1 \%$ of the measured value above $200{ }^{\circ} \mathrm{C}$. The entire experimental setup can be seen in Figure 3. When conducting testing the combustor is fired for a 5-min warm up period.

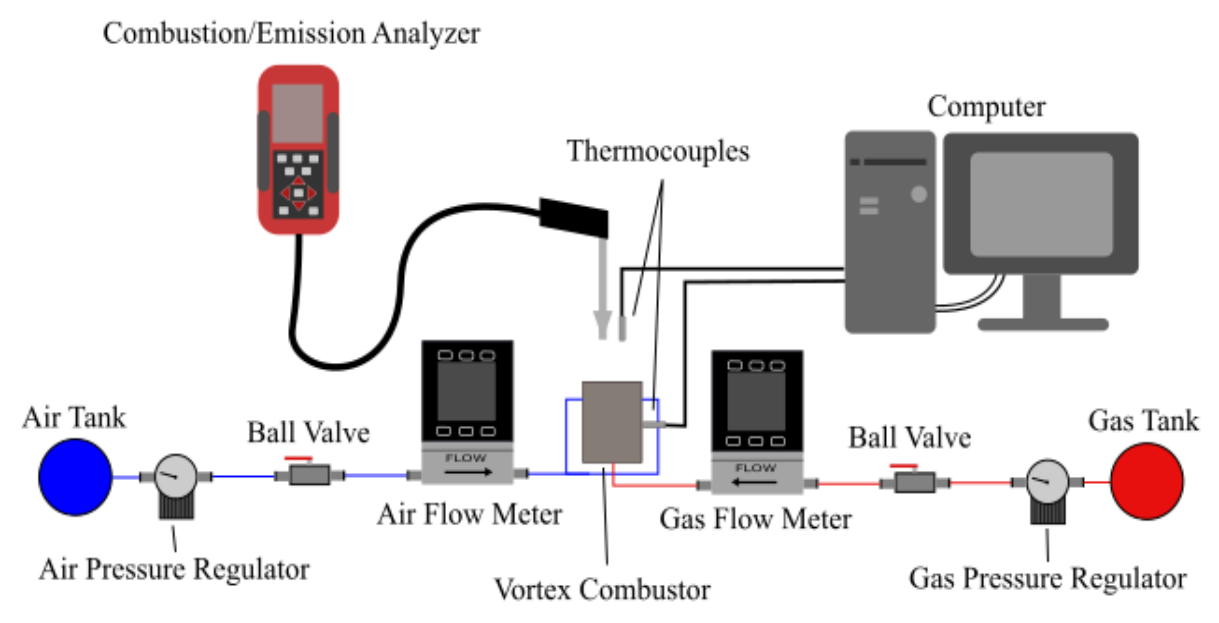

Figure 3. Experimental setup.

\section{Results and Discussion}

Heat regeneration in small-scale combustor is an important aspect of the new design. Heat generated by combustion is transferred into the walls of the combustor and is eventually transferred to the environment (by radiation and convection heat transfer mechanisms). The rate of this heat transfer depends upon the material used when constructing the combustor which in this case is 1018 steel. Heat regeneration is important for making a stable flame within the combustor and increasing the efficiency of the design and is done by preheating the air using heat generated by the combustion process that otherwise would be lost to the environment. The combustion air is preheated by flowing through channels made inside the combustor walls and the idea is to extend the length of these channels to allow for more heat transfer into the air before entering the chamber. The channels in the meso-scale combustor with thermal recuperator are 2.8 times longer than the combustor without thermal recuperator. The longer air inlets create higher inlet air temperatures which has effect on the characteristics of the combustion process. Properties that are affected include efficiencies, emissions, and temperatures. Figure 4 shows comparison between wall temperature and exhaust temperature of two combustors in warm up process at stoichiometry condition when the mass flow rate of combustion air is $80 \mathrm{mg} / \mathrm{s}$. The left axes temperature is related to the wall temperature and the right-side axes is related to exhaust temperature.

The empirically achieved flame stability limits of meso-scale combustor with/without thermal recuperator is illustrated in Figure 5. Based on this figure, the flame can be sustained between the lower limits and the upper limits (in a narrow range of equivalence ratios) for a given mass flow rate. Blow-off, stable and blow-out regions are separately shown in the graph. At a specific combustion air mass flowrate and equivalence ratio, the flame is blow off at the lower limit and blow out at the 
upper limit. In both combustors, blow off takes place for all combustion air mass flow rates when the equivalent ratio is less than 0.25 and the blow off limit improves when thermal recuperator is used. Two parameters have significant effects on the flame extinction; first blow-off extinction which occurs when residence time is not enough compared to the chemical reaction time, and second heat loss through the walls.

\section{Stochiometric Temperature Comparison $(80 \mathrm{mg} / \mathrm{s})$}

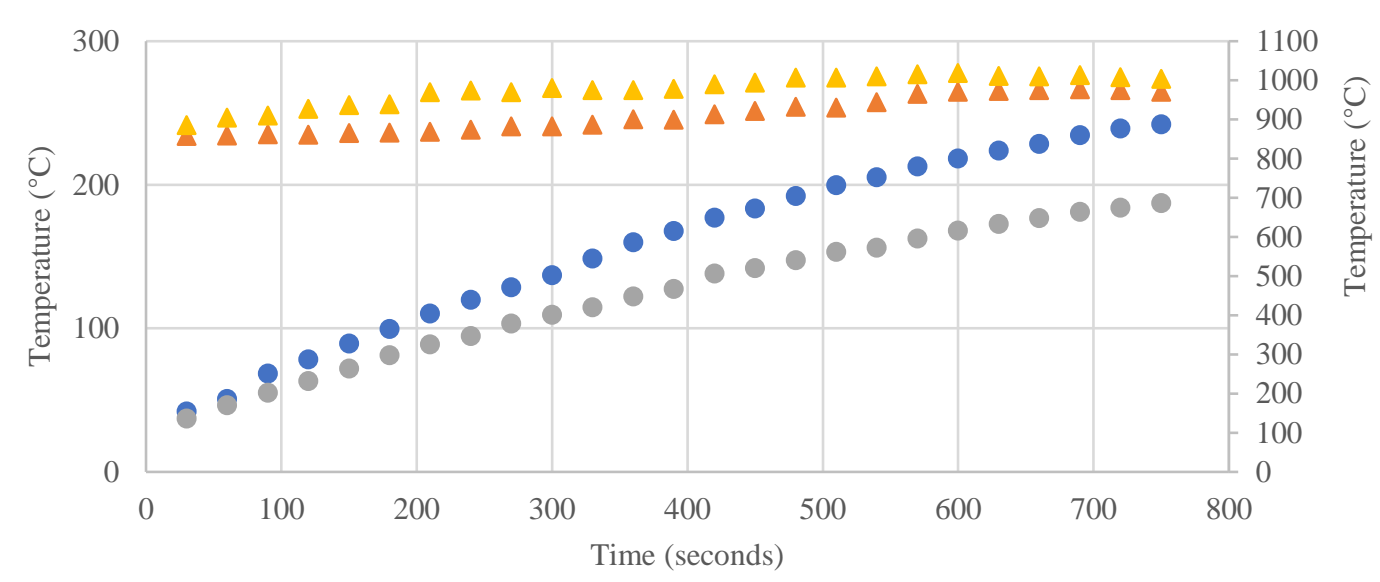

- Wall Temperature With Thermal Recuperator

- Wall Temperature Without Thermal Recuperator

$\Delta$ Exhaust Temperature With Thermal Recuperator

$\triangle$ Exhaust Temperature Without Thermal Recuperator

Figure 4. Comparison between wall temperature and exhaust temperature of two combustors in warm up process at stoichiometry condition when mass flow rate of air is $80 \mathrm{mg} / \mathrm{s}$.

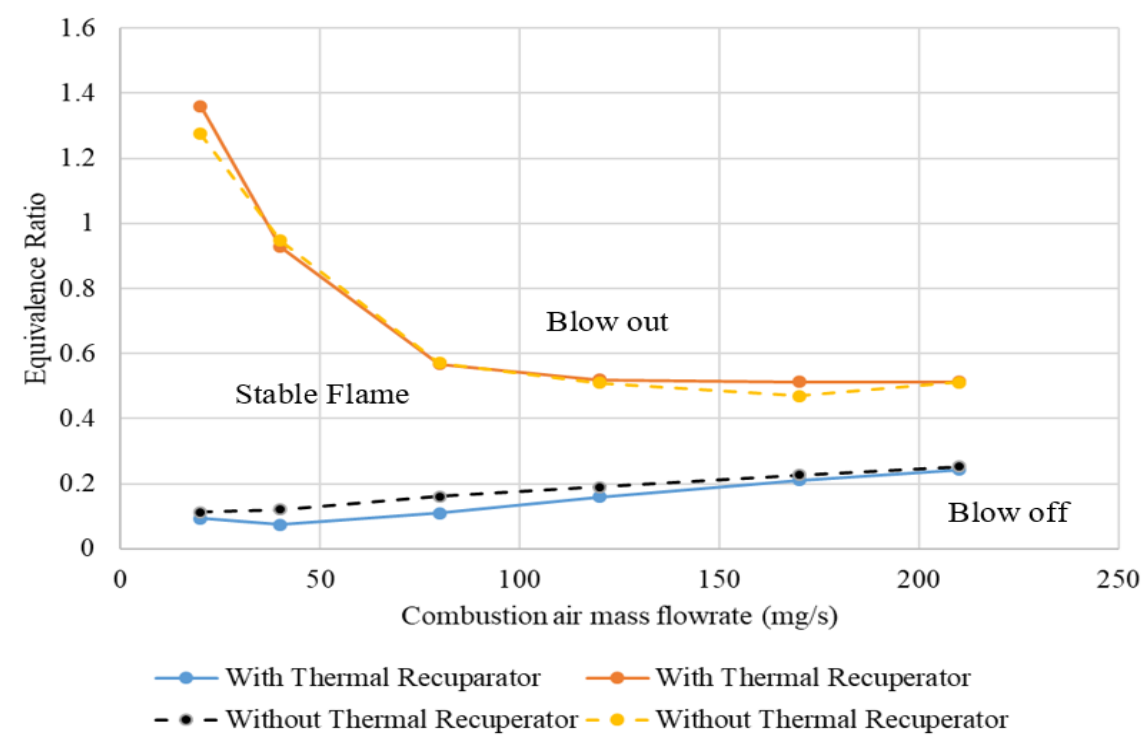

Figure 5. The stability limits of meso-scale combustor with/without thermal recuperator.

\subsection{Flame Observation}

The flame stability of the two designs was investigated and the lean flame off threshold was found for each design at various Reynolds numbers. Observations confirm that in low Reynolds numbers, the stability of flame is higher in the combustor without thermal recuperator, however in high Reynolds numbers (which is more desirable for micro-gas turbine power generation) the flame is 
more stable in low equivalence ratios in combustor with thermal recuperator. A blue flame generally indicates lean combustion while green and orange/yellow indicate a rich combustion. Images of the flames at an air flow of $80 \mathrm{mg} / \mathrm{s}$ and equivalence ratios of $0.1,0.6,1.0$, and 1.2 for each design are shown in Figure 6.
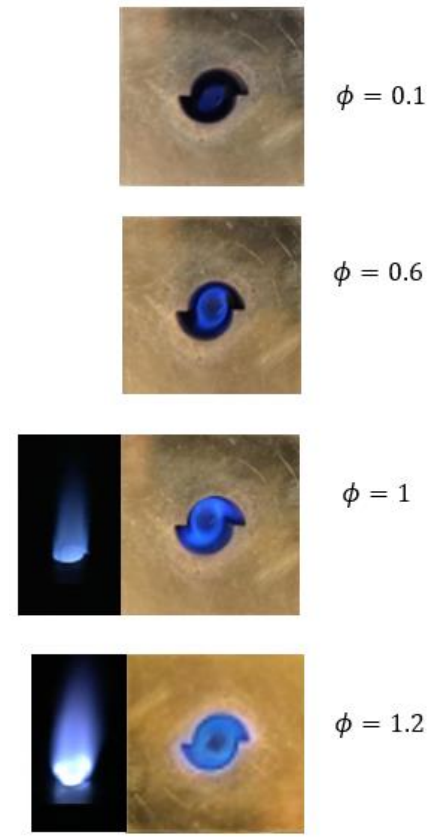

(a)
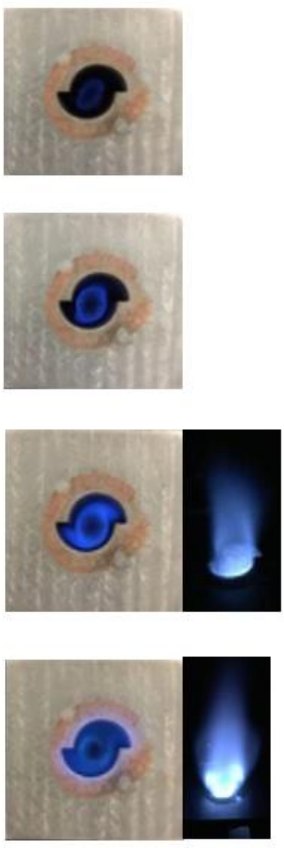

(b)

Figure 6. Photographs of flame with $80 \mathrm{mg} / \mathrm{s}$ at various equivalence ratios $(\phi)$ (a) with thermal recupertor (b) without thermal recuperator.

\subsection{Wall Temperature and Emitter Efficiency}

The flame temperature impacts on inside combustor wall temperature which depends on the equivalence ratio. Wall temperature is a factor that illustrates the rate of heat loss from the combustor which effects on the flame stability especially in small-scale combustion due to high surface to volume ratio. The wall temperature is an important factor especially when considering using thermophotovoltaic (TPV) power generation, because the main factor effecting their power output is the temperature difference between surfaces. The larger this temperature difference the greater the potential output. Even though a lot of the heat generated by the combustors is lost with the exhaust gasses the walls of the combustors reach relatively high temperatures that could be suitable for TPV generators. The wall temperatures for both designs for air flow rates of $40 \mathrm{mg} / \mathrm{s}(\operatorname{Re}=1840)$, $80 \mathrm{mg} / \mathrm{s}(\operatorname{Re}=3681), 120 \mathrm{mg} / \mathrm{s}(\operatorname{Re}=5522)$, and $170 \mathrm{mg} / \mathrm{s}(\operatorname{Re}=7822)$ in lean $(\varphi=0.1-0.9)$, stoichiometric $(\varphi=1)$ and rich $(\varphi=1.1-1.2)$ conditions are demonstrated in Figure 7.

The mean wall temperature of the combustor with thermal recuperator is higher than the combustor without thermal recuperator except in ultra-lean combustion. In high combustion air flow rates (high Reynolds number), the difference between wall temperature of two combustor increases up to 70C. Therefore, it can be estimated that the emitter efficiency of the combustor with thermal recuperator is higher than the other combustor, and consequently, the performance of micro TPV system is better in the former combustor. 
Mean Wall Temperature $(\mathrm{Re}=1840)$

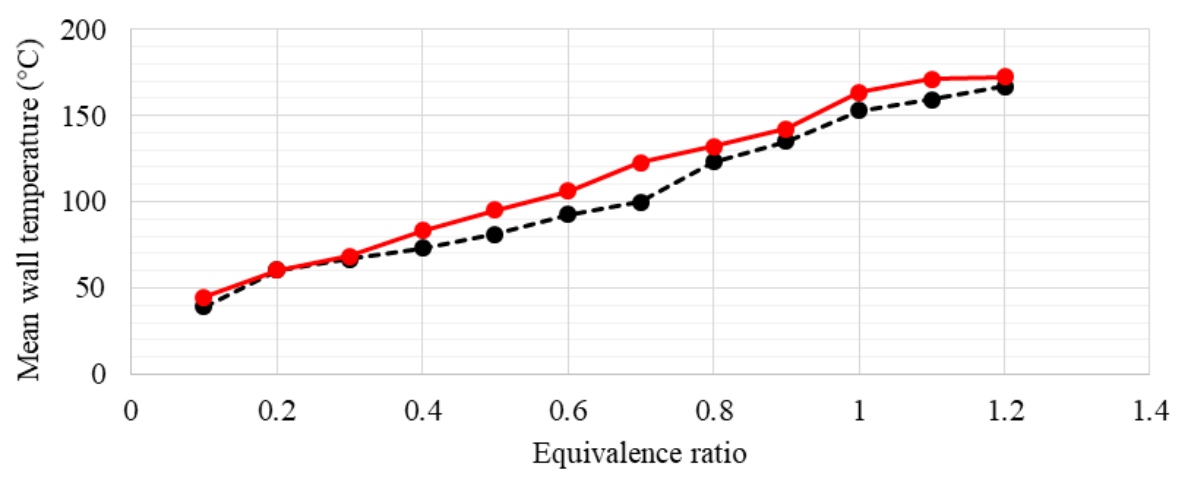

- - -- Without thermal recuperation $\longrightarrow$ With thermal recuperation

(a)

Mean Wall Temperature $(\operatorname{Re}=3681)$

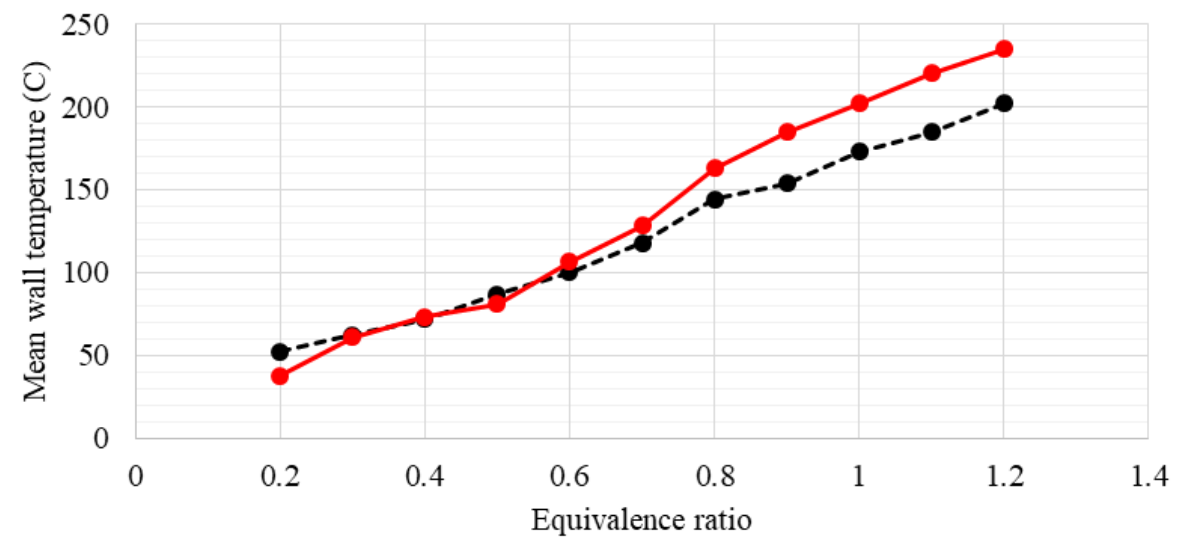

--•-- Without thermal recuperation $\longrightarrow$ With thermal recuperation

(b)

Mean Wall Temperature $(\mathrm{Re}=5522)$

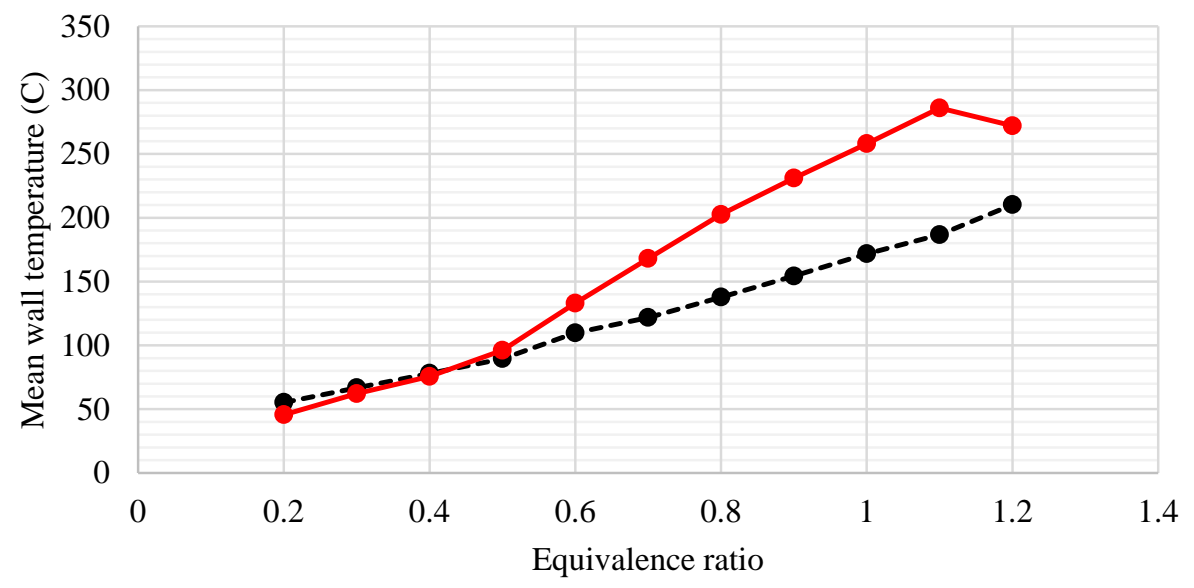

- - -- Without thermal recuperation $\quad \longrightarrow$ With thermal recuperation

(c)

Figure 7. Cont. 
Mean Wall Temperature $(\mathrm{Re}=7822)$

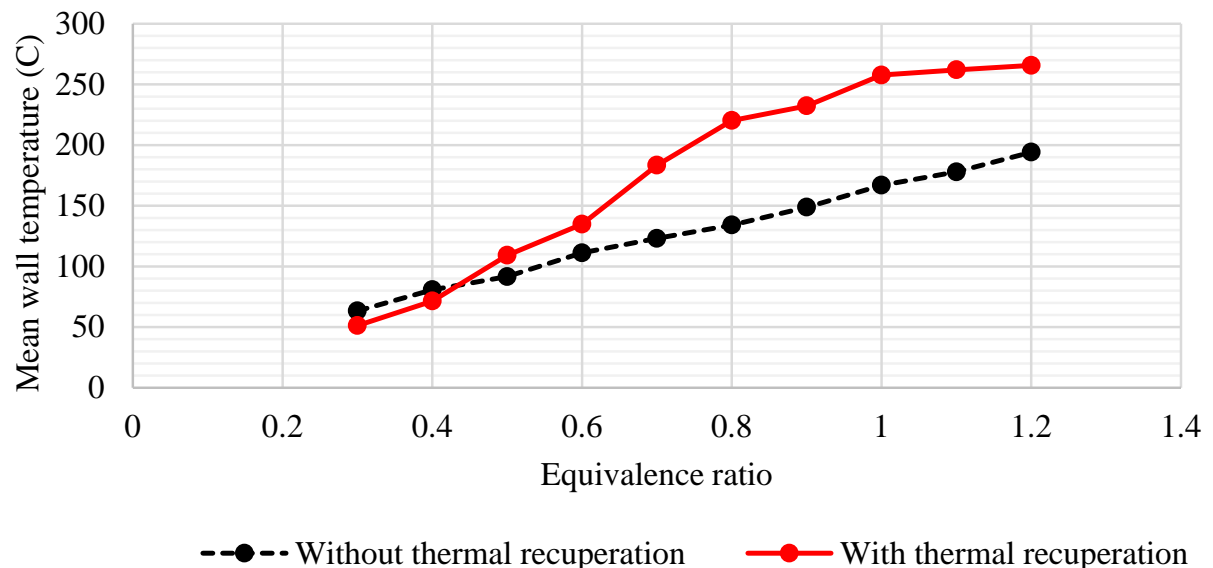

(d)

Figure 7. Mean wall temperature with respect to various air mass flow rates and various equivalence ratios. (a) $\operatorname{Re}=1840 ;$ (b) $\operatorname{Re}=3681 ;$ (c) $\operatorname{Re}=5522 ;$ (d) $\operatorname{Re}=7822$.

Although, promising progresses have been reported in energy conversion in micro TPV systems, the output power of these systems is still low for practical application. Consequently, lots of investigations have been performed on small-scale combustors to elevate efficiency and output power of the miniaturized TPV systems. Thermal radiation from small-scale combustor wall is used for TPV power generation in some cases. Hence, the emitter efficiency is an important parameter to consider when generating power using a TPV system. Some of the heat generated by combustion is transferred into the body and through the combustor walls, the more heat that is radiated by the combustor walls and less expelled with the exhaust increases the emitter efficiency. The emitter efficiency is an important parameter to consider when generating power using a TPV system. Some of the heat generated by combustion is transferred into the body and through the combustor walls, the more heat that is radiated by the combustor walls and less expelled with the exhaust increases the emitter efficiency. The term heat radiation and emitter efficiency are calculated by:

$$
\begin{gathered}
\dot{Q}_{\text {rad }}=\sum A \varepsilon \delta\left(T_{w}^{4}-T_{\infty}^{4}\right) \\
\eta=\frac{\dot{Q}_{\text {rad }}}{\dot{m}_{C H 4} \times L H V_{\mathrm{CH}_{4}}}
\end{gathered}
$$

where $A$ is the area of the combustor's wall, $\delta$ is Stephen-Boltzman constant $\left(5.67 \times 10^{-8} \mathrm{~W} / \mathrm{m}^{2} \cdot \mathrm{K}^{4}\right)$, $\varepsilon$ is the emissivity of the material, $T_{w}$ is wall temperature and $T_{\infty}$ is ambient temperature, $\dot{m}_{C H 4}$ and $\mathrm{LHV}_{\mathrm{CH}_{4}}$ are mass flowrate and lower heating value of methane respectively.

Figure 8 compares the emitter efficiency of both combustors with respect to the various equivalence ratios and combustion air inlet flowrate. According to Equation (2), since the wall temperature plays crucial role on the rate of heat radiation which is important to calculate emitter efficiency, and as it was shown in Figure 6, the wall temperature in combustor with thermal recuperator is higher than the combustor without thermal recuperator, the emitter efficiency of the former combustor is higher than later one. 
Emitter Efficiency $(\mathrm{Re}=1840)$

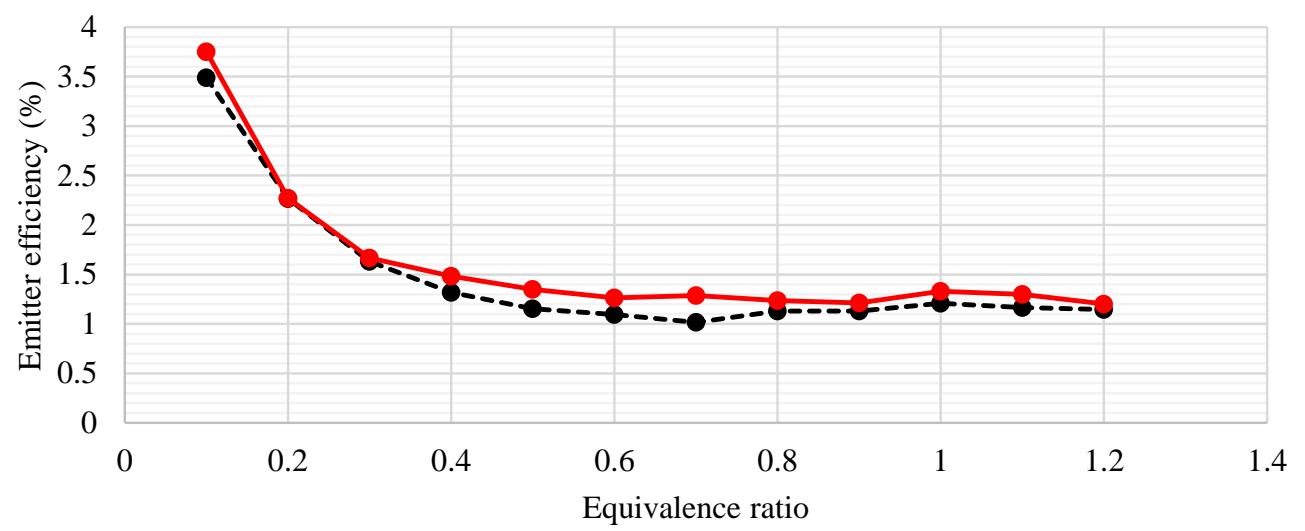

- -- Without thermal recuperation $\longrightarrow$ With thermal recuperation

(a)

Emitter Efficiency $(\mathrm{Re}=3681)$

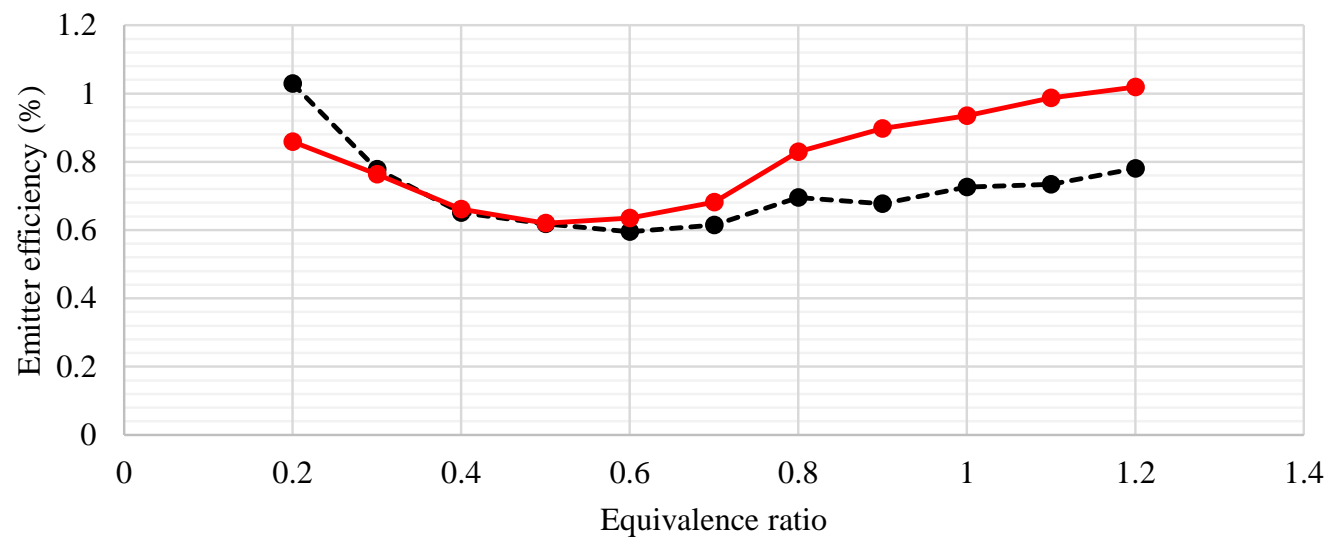

-- -- Without thermal recuperation $\longrightarrow$ With thermal recuperation

(b)

Emitter Efficiency $(\mathrm{Re}=5522)$

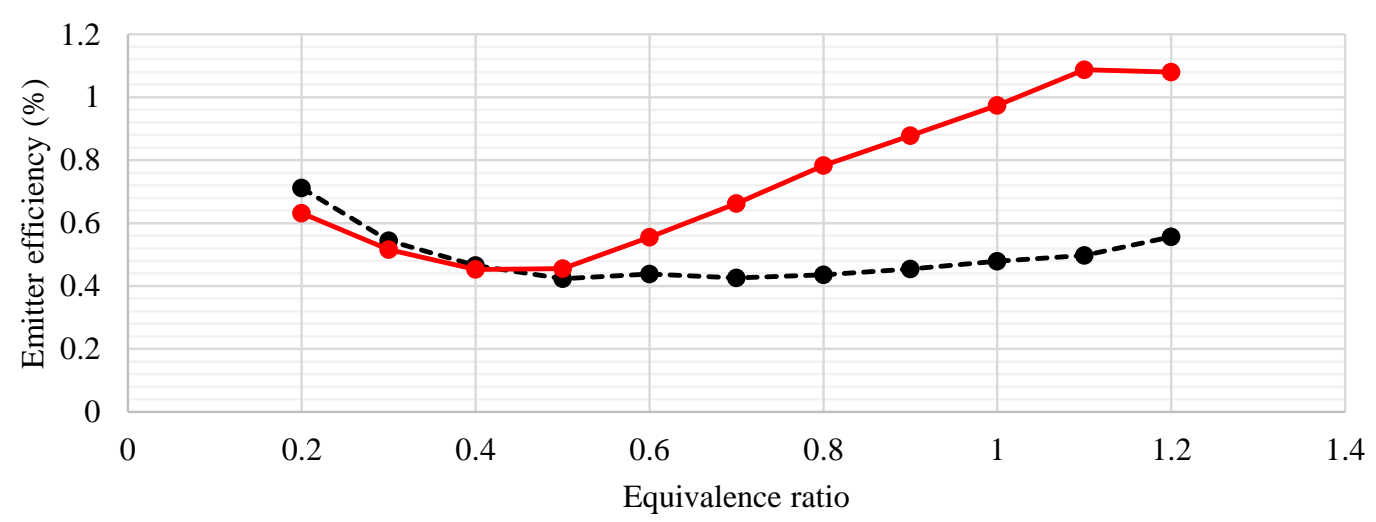

- -- Without thermal recuperation $\longrightarrow$ With thermal recuperation

(c)

Figure 8. Cont. 
Emitter Efficiency $(\mathrm{Re}=7822)$

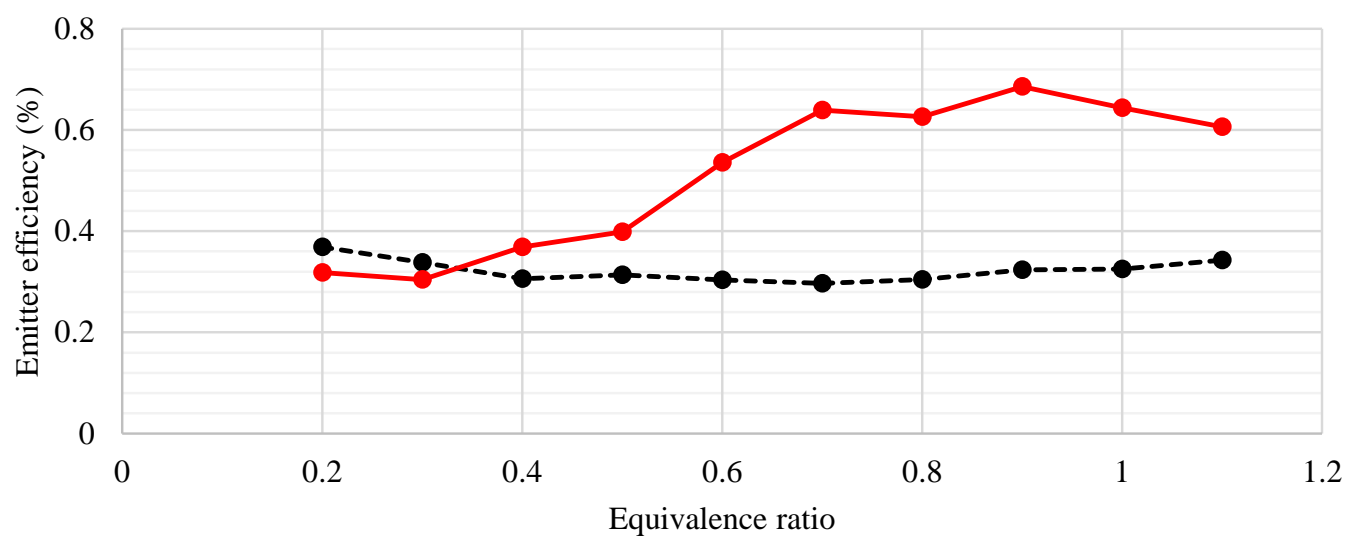

--๑--Without thermal recuperation $\longrightarrow$ With thermal recuperation

(d)

Figure 8. Emitter efficiency with respect to various air mass flow rates and various equivalence ratios.

(a) $\operatorname{Re}=1840 ;$ (b) $\operatorname{Re}=3681 ;(c) \operatorname{Re}=5522 ;(d) \operatorname{Re}=7822$.

\subsection{Exhaust Gases Temperature and Thermal Efficiency}

Since the small-scale combustor and its support structure are not thermally insulated during the experiments, heat can easily escape the combustor via radiation and convection forms. Figure 9 demonstrates the temperature of exhaust flue gases at various equivalence ratios with respect to the different combustion air flow rates.

From exhaust gases temperature graphs, it is obvious that the increase of air mass flow rate has significant effect on the exhaust gases temperature in both designs. In low Reynolds numbers, since the residence time is long, longer time is provided for heat loss from the walls, and hence the rate of heat transfer between air mass flowrate at the recuperator channel and combustor is high. Therefore, the temperature of exhaust gases at combustor with thermal recuperator is lower than the other design. However, in high Reynolds numbers, due to extremely fast flow rate of the combustion air in the channel, there is not enough time for heat transfer between the combustor and combustion air in the recuperator channel and consequently, the temperature of exhaust gases in both designs does not have significant difference. 
Exhaust Gas Temperature $(\mathrm{Re}=1840)$

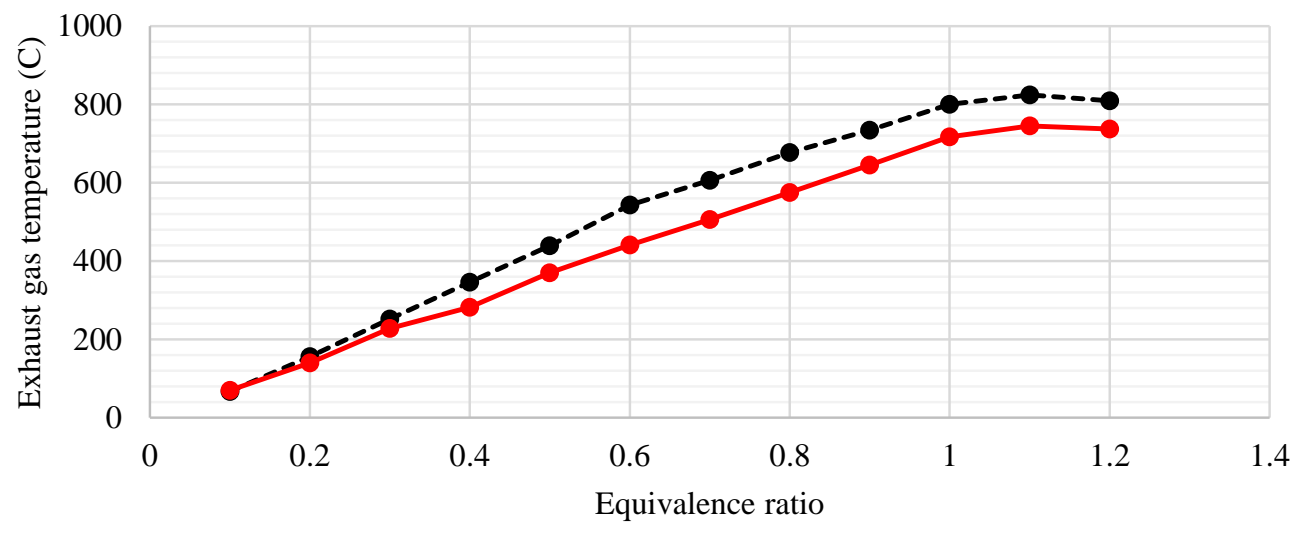

--•--Without thermal recuperation $\longrightarrow$ With thermal recuperation

(a)

Exhaust Gas Temperature $(\mathrm{Re}=3681)$

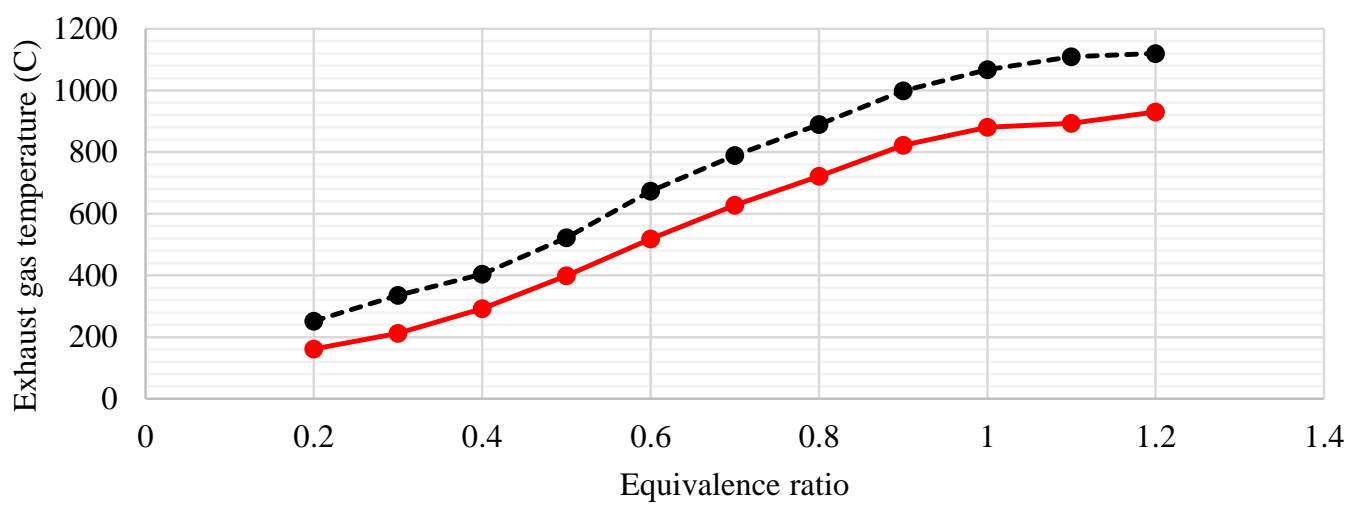

--- Without thermal recuperation $\longrightarrow$ With thermal recuperation

(b)

Exhaust Gas Temperature $(\mathrm{Re}=5522)$

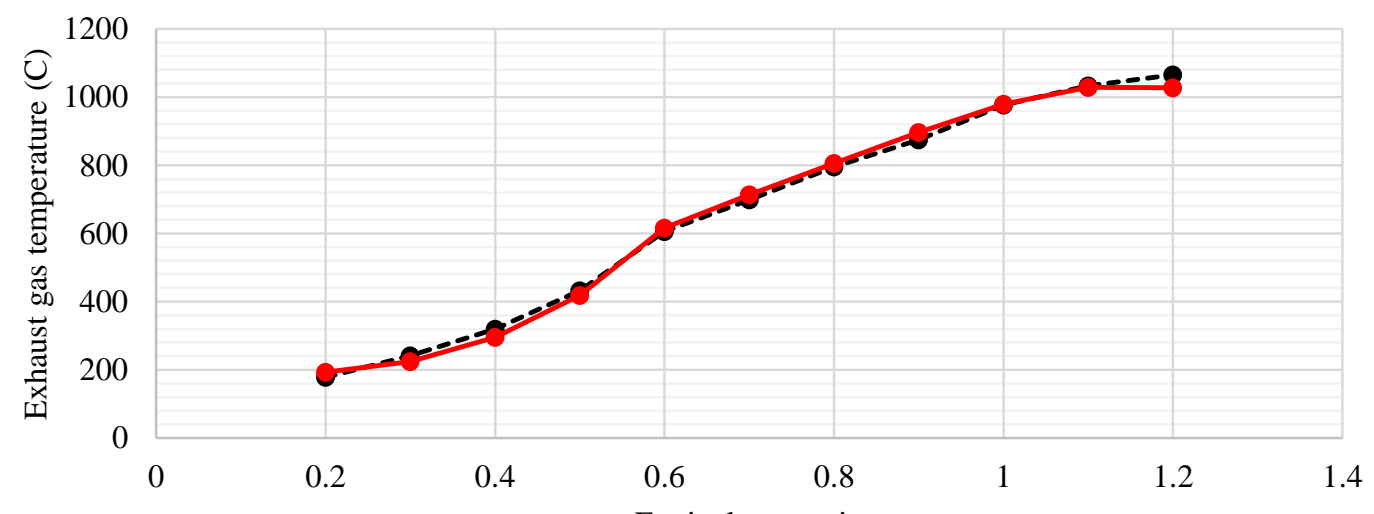

Equivalence ratio

- -- Without thermal recuperation $\longrightarrow$ With thermal recuperation

(c)

Figure 9. Cont. 
Exhaust Gas Temperature $(\mathrm{Re}=7822)$

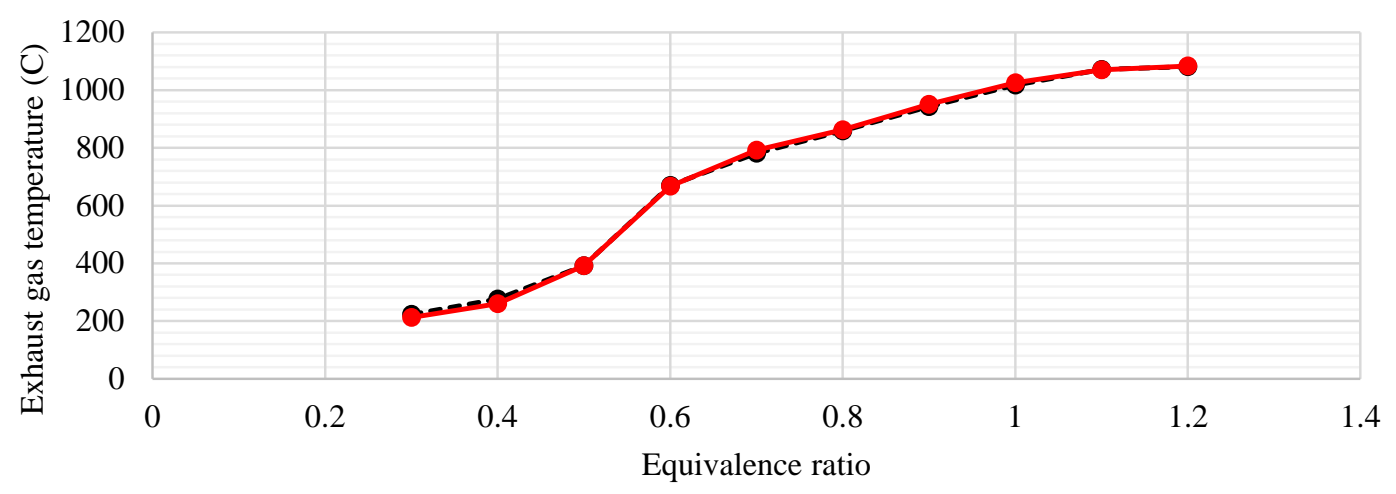

- - -- Without thermal recuperation $\longrightarrow$ With thermal recuperation

(d)

Figure 9. Temperature of exhaust gases in various equivalence ratios and different air mass flow rates. (a) $\operatorname{Re}=1840 ;$ (b) $\operatorname{Re}=3681 ;(\mathbf{c}) \operatorname{Re}=5522 ;$ (d) $\operatorname{Re}=7822$.

The heat loss from the combustor's wall $\left(\dot{Q}_{P}\right)$ is divided the heat radiation $\left(\dot{Q}_{\text {rad }}\right)$ and heat convection $\left(\dot{Q}_{\text {conv }}\right)$ :

$$
\dot{Q}_{P}=\dot{Q}_{r a d}+\dot{Q}_{c o n v}
$$

The term heat radiation is calculated by Equation (1).

To find convective heat transfer, the following equation is used:

$$
\dot{Q}_{\text {conv }}=h A\left(T_{w}-T_{\infty}\right)
$$

where $h$ is convective heat transfer coefficient, finding from Equation (5):

$$
h=\lambda \frac{N u}{L}
$$

In this equation $\lambda$ is the thermal conductivity of air at the wall temperature, $L$ is the length of the combustor's wall and $N u$ is the Nusselt number given by:

$$
N u=0.68+\frac{0.67(G r P r)^{\frac{1}{4}}}{\left[1+(0.492 / P r)^{\frac{9}{16}}\right]^{\frac{4}{9}}}
$$

In Equation (6), Gr is the Grashof number and $\operatorname{Pr}$ is the Prandtl number:

$$
\begin{gathered}
G r=g \beta\left(T_{w}-T_{\infty}\right) \frac{L^{3}}{v^{2}} \\
\operatorname{Pr}=\frac{v}{\alpha}
\end{gathered}
$$

where $g$ is Earth's acceleration due to gravity. The volumetric thermal expansion coefficient $\beta$, the kinematic viscosity $v$ and the thermal diffusivity $\alpha$ of air are all evaluated at the film temperature:

$$
T_{f}=\frac{T_{w}+T_{\infty}}{2}
$$

The thermal efficiency of the combustor is defined as the ratio of the total thermal output that can be harvested over the total thermal input: 


$$
\eta=\frac{\left(\dot{m} C_{P 0} T_{0 u t}-\dot{m} C_{P i} T_{i n}\right)+\dot{Q}_{P}}{\dot{m}_{f} L H V}
$$

Figure 10 shows thermal efficiency of meso-scale combustor with/without thermal recuperator in various equivalence ratios and different air mass flow rates. Figure 10 clearly illustrates that using thermal recuperator increases the thermal efficiency of the system significantly. Thermal efficiency of the combustion system increases up to $10 \%$ when thermal recuperator is employed especially in moderate Reynolds numbers (combustion air flow rate is $120 \mathrm{mg} / \mathrm{s}$ ) which is desirable condition for micro-electricity generation using micro-turbine.

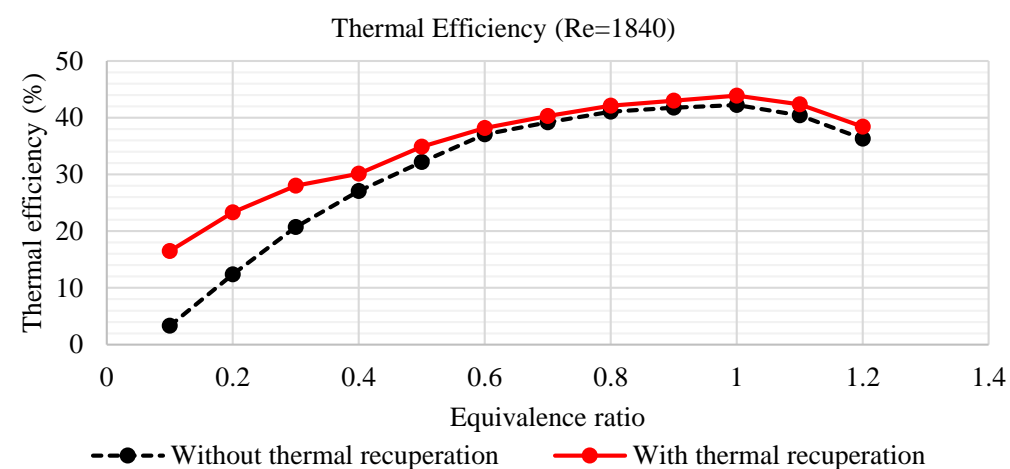

(a)

Thermal Efficiency $(\operatorname{Re}=3681)$

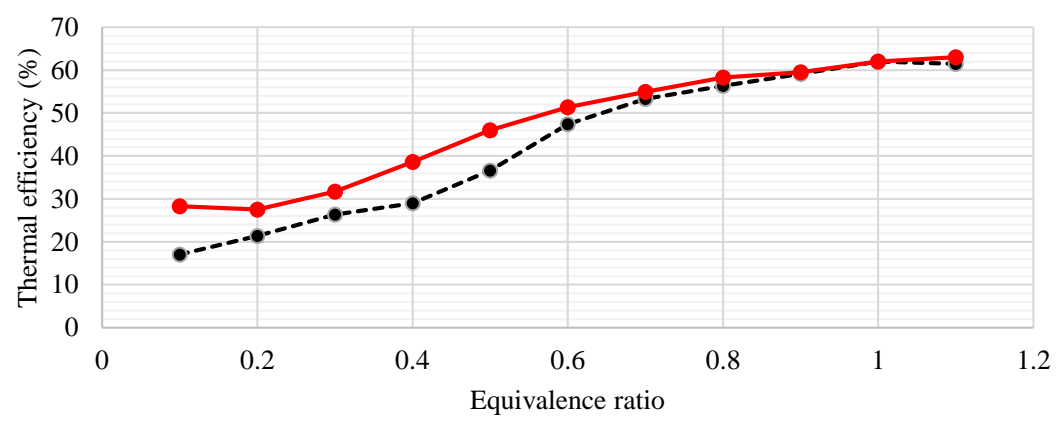

--•-- Without thermal recuperation $\longrightarrow$ With thermal recuperation

(b)

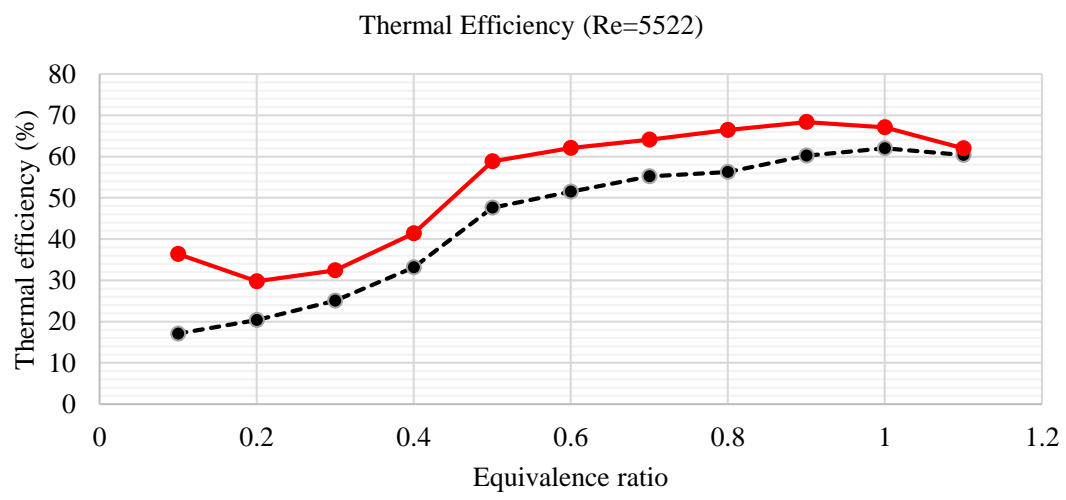

--๑-- Without thermal recuperation $\longrightarrow$ With thermal recuperation

(c)

Figure 10. Cont. 


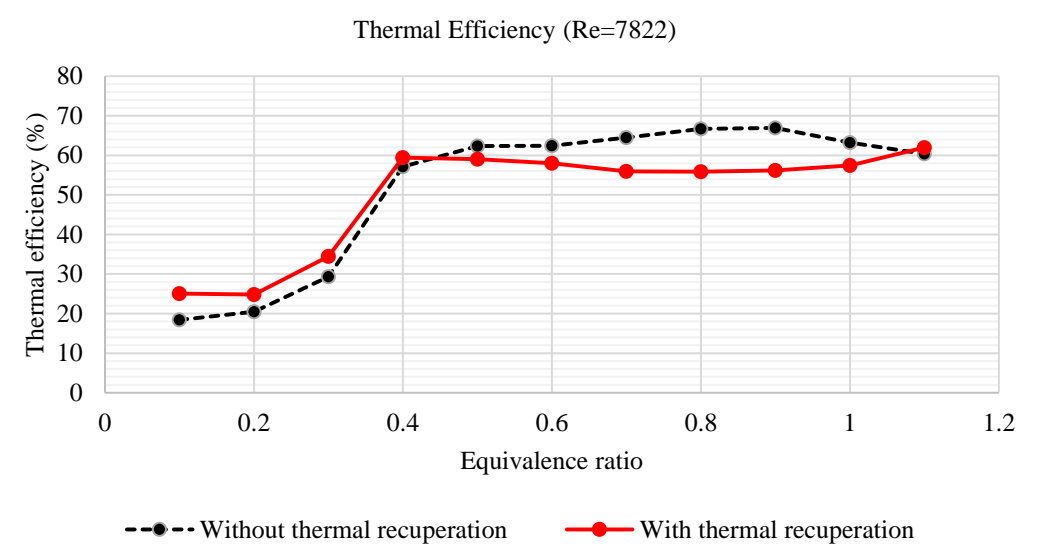

(d)

Figure 10. Thermal efficiency of meso-scale combustor with/without thermal recuperator in various equivalence ratios and different air mass flow rates. (a) $\operatorname{Re}=1840$; (b) $\operatorname{Re}=3681$; (c) $\operatorname{Re}=5522$; (d) $\operatorname{Re}=7822$.

\section{Conclusions}

Due to high surface to volume ratio in small-scale combustors, heat loss from the combustor's wall increases drastically and flame quenching is inevitable. To solve this problem, the effects of using thermal recuperation on the characteristics of small-scale combustion was experimentally investigated. Two asymmetry non-premixed vortex meso-scale combustors with/without thermal recuperator were employed and it was found that the wall temperature of combustor increases by using thermal recuperator. Hence, emitter efficiency was found higher in meso-scale vortex system with thermal recuperator which provides a good condition for thermophotovoltaic power generation. Moreover, in moderate Reynolds numbers of combustion air flow, thermal efficiency of the combustion system increases up to $10 \%$ when thermal recuperator is used which is very important for micro-electricity generation using micro-turbine. The results of this work are useful for those researchers and engineers who are dealing with developing combustion-based micro-power generation.

Author Contributions: The design of the system and analysis of the results was done by the S.E.H. and the experiments were run by the E.O. under the first author supervision. The whole manuscript was reviewed and modified by the J.K. and J.L.

Funding: This research was funded by National Space and Aeronautics Administration Established Program to Stimulate Competitive Research (NASA EPSCoR) Research Infrastructure Development Program grant number NNX15AK32A.

Acknowledgments: The authors would like to appreciate "Arkansas Space Grant Consortium" and the higher administration of Arkansas Tech University for their valuable support. We gratefully acknowledge the support from Tomasz G. Drozda at Hypersonic Air-Breathing Propulsion Branch NASA Langley Research Center.

Conflicts of Interest: The authors declare no conflict of interest.

\section{Nomenclature}

A Area of the combustor's wall

$h \quad$ Convective heat transfer coefficient

$L \quad$ The length of the combustor's wall

Gr Grashof number

$\mathrm{Nu} \quad$ Nusselt number

Pr Prandtl number

$g \quad$ Earth's acceleration due to gravity

$T_{f} \quad$ Film temperature

$T_{w} \quad$ Wall temperature

$T_{\infty} \quad$ Ambient temperature

$\mathrm{LHV}_{\mathrm{CH}_{4}} \quad$ Lower heating value of methane 


$\begin{array}{ll}\dot{m}_{\mathrm{CH} 4} & \text { Mass flowrate of methane } \\ \dot{Q}_{P} & \text { Heat loss from the combustor's wall } \\ \dot{Q}_{\text {rad }} & \text { Heat radiation } \\ \dot{Q}_{\text {conv }} & \text { Heat convection } \\ \lambda & \text { Thermal conductivity of air at the wall temperature } \\ \delta & \text { Stephen-Boltzman constant }\left(5.67 \times 10^{-8} \mathrm{~W} / \mathrm{m}^{2} \cdot \mathrm{K}^{4}\right) \\ \varepsilon & \text { Emissivity of the material } \\ \beta & \text { Volumetric thermal expansion coefficient } \\ v & \text { Kinematic viscosity } \\ \alpha & \text { Thermal diffusivity of air } \\ \eta & \text { Thermal efficiency of the combustor }\end{array}$

\section{References}

1. Hosseini, S.E.; Wahid, M.A. Investigation of bluff-body micro-flameless combustion. Energy Convers. Manag. 2014, 88, 120-128. [CrossRef]

2. Khaleghi, M.; Hosseini, S.E.; Wahid, M.A. Vortex combustion and heat transfer in meso-scale with thermal recuperation. Int. Commun. Heat Mass Transf. 2015, 66, 250-258. [CrossRef]

3. Yao, S.-C.; Tang, X.; Hsieh, C.-C.; Alyousef, Y.; Vladimer, M.; Fedder, G.K.; Amon, C.H. Micro-electromechanical systems (MEMS)-based micro-scale direct methanol fuel cell development. Energy 2006, 31, 636-649. [CrossRef]

4. Bagheri, G.; Hosseini, S.E.; Wahid, M.A. Effects of bluff body shape on the flame stability in premixed micro-combustion of hydrogen-air mixture. Appl. Therm. Eng. 2014, 67, 266-272. [CrossRef]

5. Sirignano, W.A.; Pham, T.K.; Dunn-Rankin, D. Miniature-scale liquid-fuel-film combustor. Proc. Combust. Inst. 2002, 29, 925-931. [CrossRef]

6. Khaleghi, M.; Hosseini, S.E.; Abdul Wahid, M. Investigations of asymmetric non-premixed meso-scale vortex combustion. Appl. Therm. Eng. 2015, 81, 140-153. [CrossRef]

7. Xu, B.; Ju, Y. Concentration slip and its impact on heterogeneous combustion in a micro scale chemical reactor. Chem. Eng. Sci. 2005, 60, 3561-3572. [CrossRef]

8. Bagheri, G.; Hosseini, S.E. Impacts of inner/outer reactor heat recirculation on the characteristic of micro-scale combustion system. Energy Convers. Manag. 2015, 105. [CrossRef]

9. Li, J.; Li, Q.; Shi, J.; Liu, X.; Guo, Z. Numerical study on heat recirculation in a porous micro-combustor. Combust. Flame 2016, 171, 152-161. [CrossRef]

10. Wierzbicki, T.A.; Lee, I.C.; Gupta, A.K. Combustion of propane with Pt and Rh catalysts in a meso-scale heat recirculating combustor. Appl. Energy 2014, 130, 350-356. [CrossRef]

11. Wang, Y. A Numerical Study of Combustion in Meso-Scale Vortex Chambers. Doctor's degree, The Pennsylvania State University, Pennsylvania, PA, USA, 2006.

12. Kim, N.; Kato, S.; Kataoka, T.; Yokomori, T.; Maruyama, S.; Fujimori, T.; Maruta, K. Flame stabilization and emission of small Swiss-roll combustors as heaters. Combust. Flame 2005, 141, 229-240. [CrossRef]

13. Cho, J.-H.; Lin, C.S.; Richards, C.D.; Richards, R.F.; Ahn, J.; Ronney, P.D. Demonstration of an external combustion micro-heat engine. Proc. Combust. Inst. 2009, 32, 3099-3105. [CrossRef]

14. Minotti, A.; Sciubba, E.; Minotti, A.; Sciubba, E. LES of a Meso Combustion Chamber with a Detailed Chemistry Model: Comparison between the Flamelet and EDC Models. Energies 2010, 3, 1943-1959. [CrossRef]

15. Fan, A.; Zhang, H.; Wan, J. Numerical investigation on flame blow-off limit of a novel microscale Swiss-roll combustor with a bluff-body. Energy 2017, 123, 252-259. [CrossRef]

16. Chen, M.; Buckmaster, J. Modelling of combustion and heat transfer in 'Swiss roll' micro-scale combustors. Combust. Theory Model. 2004, 8, 701-720. [CrossRef]

17. Il Kim, N.; Aizumi, S.; Yokomori, T.; Kato, S.; Fujimori, T.; Maruta, K. Development and scale effects of small Swiss-roll combustors. Proc. Combust. Inst. 2007, 31, 3243-3250. [CrossRef] 
18. Minotti, A.; Teofilatto, P.; Minotti, A.; Teofilatto, P. Swirling Combustor Energy Converter: H2/Air Simulations of Separated Chambers. Energies 2015, 8, 9930-9945. [CrossRef]

19. Gabler, H.C.; Yetter, R.A.; Glassman, I. Asymmetric Whirl Combustion: A New Approach for Non-Premixed Low NOx Gas Turbine Combustor Design. In Proceedings of the 34th AIAA/ASME/SAE/ASEE Joint Propulsion Conference and Exhibit, Joint Propulsion Conferences, Cleveland, OH, USA, 13-15 July 1998; pp. 1-11.

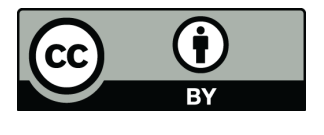

(c) 2018 by the authors. Licensee MDPI, Basel, Switzerland. This article is an open access article distributed under the terms and conditions of the Creative Commons Attribution (CC BY) license (http://creativecommons.org/licenses/by/4.0/). 